\title{
Causes of Preterm and Low Birth Weight Neonatal Mortality in a Rural Community in Kenya: Evidence From Verbal and Social Autopsy
}

Beatrice Olack ( $\square$ olackb@gmail.com )

Centre for Clinical Research, Kenya Medical Research Institute P.O Box 54840 00200, Nairobi Kenya.

Nicole Santos

University of California San Francisco

Mary Inziani

Kenya Medical Research Institute

Vincent Moshi

Kenya Medical Research Institute

Polycarp Oyoo

Kenya Medical Research Institute

Grace Nalwa

Maseno University School of Medicine

Linet Ouma

Kenya Medical Research Institute

Christopher Otare

Kenya Medical Research Institute

Dilys Walker

University of California San Francisco

Phelgona Apondi Otieno

Kenya Medical Research Institute https://orcid.org/0000-0002-2927-9848

\section{Research article}

Keywords: mortality, low birth weight (LBW), preterm neonates, asphyxia

Posted Date: October 5th, 2020

DOl: https://doi.org/10.21203/rs.3.rs-76613/v1

License: (c) (1) This work is licensed under a Creative Commons Attribution 4.0 International License.

Read Full License 


\section{Abstract}

\section{Background}

Under-five mortality in Kenya has declined over the past two decades. However, the reduction in the neonatal mortality rate has remained stagnant. In a country with weak civil registration and vital statistics systems, there is an evident gap in documentation of mortality and its causes among low birth weight (LBW) and preterm neonates. We aimed to establish causes of neonatal LBW and preterm mortality in Migori County, among participants of the PTBI-K (Preterm Birth Initiative-Kenya) study.

\section{Methods}

This was a cross sectional study whereby Verbal and social autopsy (VASA) interviews were conducted with caregivers of deceased LBW and preterm neonates delivered within selected 17 health facilities in Migori County, Kenya. The probable cause of death was assigned using the WHO International Classification of Diseases (ICD-10).

\section{Results}

Between January 2017 to December 2018, 3175 babies were born preterm or LBW, and 162 (5.1\%) died in the first 28 days of life in 17 participating health facilities in the PTBI-K project. VASA was conducted among $88(53.7 \%)$ neonatal deaths. Almost half $(38,43.2 \%)$ of the deaths occurred within the first 24 hours of life. Birth asphyxia (45.5\%), neonatal sepsis (26.1\%), respiratory distress syndrome (12.5\%) and hypothermia $(11.0 \%)$ were the leading causes of death. In the early neonatal period, majority $(54.3 \%)$ of the neonates succumbed to asphyxia while in the late neonatal period majority $(66.7 \%)$ succumbed to sepsis. Delay in seeking medical care was reported for $4(5.8 \%)$ of the neonatal deaths.

\section{Conclusion}

Deaths among LBW and preterm neonates occur early in life due to preventable causes. This calls for enhanced intrapartum and immediate postpartum care interventions targeting asphyxia, sepsis, respiratory distress syndrome and hypothermia.

\section{Background}

The World Health Organization (WHO) estimates that 15 million babies are born preterm annually and approximately one million succumb to death in their first 4 weeks of life due to complications of prematurity[1]. Preterm birth has been reported to be the leading cause of neonatal death [1-5]. Infants born preterm are four times more likely than term infants to die during the neonatal period (first 28 days) and infancy (first year) [6]. Mortality rates increase proportionally with decreasing gestational age or birth weight $[7,8]$. Preterm babies born in developed countries have almost ten times better survival rates compared to those born in low-resource settings $[9,10]$. South Asia and sub-Saharan Africa account for over three-quarters of the world's newborn deaths due to preterm birth and its complications [11]. 
Babies are born weighing less than 2500 grams are termed low birth weight. Their births can be related to premature delivery, as well as, associated with the restriction of intrauterine growth or the relationship between both situations [12]. In sub-Saharan Africa, 14 percent of babies are born with low birthweight (LBW), and have an infant mortality rate 77 times higher than normal-weight babies [12].

Most deaths in preterm babies in the developing nations occur from preventable causes such as infection, asphyxia, hypothermia, and hypoglycemia. Moreover, $>80 \%$ are born between 32 and 37 weeks of gestation (moderate/late preterm), and many die needlessly for lack of simple, essential care such as warmth and feeding support [13]. The Every Newborn Action Plan (ENAP), a road map to reduce preventable neonatal deaths advocates for strengthening death surveillance through supporting the community in reporting and reviewing causes of maternal and neonatal deaths $[14,15]$.

Kenya ranks sixth among the African countries with the most newborn deaths [16]. The 2014 Kenyan demographic health survey documents that five years preceding the survey under-five mortality rate declined from $74 / 1000$ to $52 / 1,000$ live births and infant mortality decreased from $52 / 1,000$ to $39 / 1,000$ live births however, neonatal mortality rates declined from $31 / 1,000$ to only $22 / 1,000$ live births [17]. Despite the progressive decline in under five and infant mortality, there has been slow progress in reducing neonatal mortality.

Understanding causes of and circumstances preceding preterm neonate death, is essential for accelerating progress towards Sustainable Development Goal (SDG) 3, target 3.2, that aims at reducing neonatal mortality rates to 12 per 1,000 live births by 2030 . Integrating verbal and social autopsy has given compelling results for improving maternal and child survival estimates. In Burkina Faso and Indonesia, D'Ambruoso et al. demonstrated that VASA results can be used for planning and prioritization of interventions that improve maternal health [18]. In emergencies, VASA has been used to identify gaps in civil registration and strengthen health systems in times of crisis. In Niger, the use of VASA data with effective feedback led to evidence-based decision-making and program improvement in child health [1821].

Effective and efficient Civil Registration and Vital Statistics (CRVS) is the gold standard for generating reliable data on demography, mortality, and causes of death data [22], however, it is estimated that more than half the deaths that occur among Kenyan neonates remain unreported [23].

This study aimed to determine the causes of death among preterm and low birth weight (LBW) infants born in selected health facilities in Migori county between January 1, 2017, to December 31, 2018.

\section{Methods}

\section{Study Design}

We conducted a cross-sectional study for all preterm and low birth weight (LBW) neonatal deaths that occurred January 1, 2017, to December 31, 2018 in 17 selected health facilities in Migori County, Western 
Kenya.

\section{Study Population}

The study population included a cohort of preterm and LBW infants enrolled in an implementation science study conducted by the Preterm Birth Initiative (PTBi), collaboration among Kenya Medical Research Institute (KEMRI), Makerere University and University of California, San Francisco. The study area and inclusion criteria for enrollment are described in detail in the published study protocol [24]. In Kenya, all babies who were born preterm or LBW in the 17 PTBi participating health facilities were followed up to day 28 to determine their status. They were eligible for follow up if their birth weight was $<2500$ grams or birth weight $\geq 2500$ and $<3000$ grams and documented or calculated gestational age less than 37 weeks.

The babies who died before discharge were identified from the maternity register and the ones who died post-discharge were identified from the PTBi database. We abstracted identifying contact information for the mothers or primary caregiver of the deceased infants onto the study locator form. We used the provided contact information to reach out to the mothers/caregivers of the deceased for an appointment but in case the contact information was missing, or the provided contact was unreachable, Community Health Volunteers traced the study participant. The caregivers of babies who had died within 28 days of life were invited to participate in the study.

\section{Data collection}

Households were visited by research assistants trained on VASA to administer the VASA questionnaire. This was done at least two weeks after the death of the baby, to allow for mourning period. The appropriate respondent was the person involved in primary care for the neonate before he/she died. In most cases this would be the mother, however, secondary respondents were allowed, if necessary, to capture information on all phases of the illness, including the mother's pregnancy and delivery, during which she may herself have been too ill and unaware of the neonates' condition. For respondents who had multiple neonatal deaths, the questionnaire was administered for each baby except for the sociodemographic section.

We used the VASA questionnaire for data collection. This questionnaire was adapted from the WHO standardized verbal autopsy questionnaires for deaths that occur before 28 days [25] and social autopsy from the Child Health Epidemiology Reference Group (CHERG). The questionnaire is divided into three main sections; the first section covers general information for deceased neonates, demographics of the deceased, household and socio-demographic characteristics of the respondent. The second section covers the circumstances surrounding the child's death, including signs and symptoms of any illness, the caregiver's perception of the illness, actions taken and care sought. Any barriers to seeking care are also noted. In addition to neonatal deaths, this section also asks questions about the maternal history, including the mother's antenatal care and care-seeking for obstetric complications, and about newborn care before the illness. The third section is an open narrative that allows the caregiver to narrate about the 
baby's illness and events preceding death in his or her own words. Any health records provided by the caregiver describing treatment the child received were also noted.

\section{Assigning cause of death}

To assign a probable cause of death, two clinicians trained on the WHO International Classification of Diseases (ICD 10) independently reviewed the signs and symptoms recorded on the questionnaires. If the same diagnosis was reached by the two physicians, this was accepted as the probable cause of death. If there was a discrepancy between diagnoses, an independent third physician was involved to determine a consensus on the probable cause of death.

\section{Data management and analysis}

Completed questionnaires were checked for completeness, validity and reliability. Data were entered into a Microsoft Access database then transferred into Stata 12 statistical software for cleaning and analysis. Descriptive statistics presented measures of central tendencies for quantitative data, including mean (standard deviation), median (range) and frequency distributions (frequencies and percentages). Data were presented in tables and graphs.

\section{Ethical Considerations}

The study received approval from KEMRI's Scientific and Ethical Review Unit (SERU) approval number 3595. Written informed consents were obtained from study participants in their preferred local language after they received full information about the study.

\section{Results}

During the study period (January 1, 2017, to December 31, 2018) 3204 (8.0\%) babies were born preterm or LBW and a total of $162(5.1 \%)$ neonates died during the study period. Among the neonates who died, we conducted VASA for 88 (53.7\%) deaths. Fig 1 illustrates the flow of the study population.

Socio-demographic, household and obstetric characteristics of mothers and characteristics of the deceased neonates are shown in Table 1. A total of 82 mothers were interviewed, among them were six mothers who had multiple births. The majority of the mothers 70 (85.4\%) were above 19 years and all had some formal education. Farming was the mother's main occupation. The distribution of male and female neonates who died was similar. Over three-quarters number of the babies died in the health facilities within their first week of life. Breast feeding within the first hour was initiated among 53/84 eligible neonates while kangaroo care was practiced on only one neonate.

\section{Table 1: Characteristics of mothers and deceased neonates}




\begin{tabular}{|c|c|}
\hline \multicolumn{2}{|c|}{ Mothers of deceased preterm babies $(n=82)$} \\
\hline Age in Years & $\mathrm{n}(\%)$ \\
\hline$\leq 19$ & $12(14.6)$ \\
\hline $20-24$ & $20(24.4)$ \\
\hline$>24$ & $50(51.0)$ \\
\hline \multicolumn{2}{|l|}{ Maternal Education } \\
\hline Primary & $34(41.5)$ \\
\hline Secondary & $40(48.8)$ \\
\hline Tertiary + & $8(9.9)$ \\
\hline \multicolumn{2}{|l|}{ Mothers Occupation } \\
\hline Farmer & $31(37.8)$ \\
\hline Unemployed & $25(30.5)$ \\
\hline Employed & $6(7.3)$ \\
\hline Casual labourer & $20(24.4)$ \\
\hline \multicolumn{2}{|l|}{ Source of cooking energy } \\
\hline Firewood & $51(62.2)$ \\
\hline Charcoal & $25(30.5)$ \\
\hline Other & $6(7.3)$ \\
\hline \multicolumn{2}{|l|}{ Multiple gestations } \\
\hline Yes & $6(7.3 \%)$ \\
\hline No & $76(92.7 \%)$ \\
\hline \multicolumn{2}{|l|}{ Mode of delivery } \\
\hline Spontaneous vertex delivery & $57(69.5)$ \\
\hline Caesarean section & $12(14.6)$ \\
\hline Breech delivery & $11(13.4)$ \\
\hline Assisted vaginal delivery & $2(2.4)$ \\
\hline \multicolumn{2}{|c|}{ Characteristic of deceased neonates $n=88$} \\
\hline Male & $40(45.5)$ \\
\hline Female & 48 (54.6) \\
\hline
\end{tabular}




\begin{tabular}{|ll|}
\hline$<28$ & $20(22.7)$ \\
\hline 28 to $<32$ & $19(21.6)$ \\
32 to $<37$ & $32(36.4)$ \\
$\geq 37$ & $17(19.3)$ \\
\hline Weight at birth & \\
\hline$<1000$ & $17(19.3)$ \\
\hline 1000 to $<1500$ & $27(30.7)$ \\
\hline 1500 to $<2000$ & $17(19.3)$ \\
\hline 2000 to $<2500$ & $12(13.6)$ \\
\hline$\geq 2500$ & $15(17.1)$ \\
\hline Place of death & \\
\hline Health facility & $69(78.4)$ \\
\hline Home & $12(13.6)$ \\
\hline En route to a health facility & $2(2.3)$ \\
\hline Informal health provider & $5(5.7)$ \\
\hline
\end{tabular}

\section{Care pathway for the deceased neonates}

Mothers of 84 neonates who died recognized some signs and symptoms of the baby's illness. The symptoms commonly reported were difficulty in breathing (59.1\%), fast breathing (12.5\%) and feeling cold to touch (11.4\%) among others listed in Table 2 below. Figure 2 illustrates the care seeking pathway to the deceased neonates. Four babies died immediately after birth while 20 babies died suddenly at the health facility before discharge. Formal care defined as care by a government-recognized medical practitioner, was administered to $33 / 57$ (57.9\%) babies at the health facility before discharge. Among thirty one babies who had been previously discharged from the health facility to go home, formal care was sought for $26 / 31$ (83.9\%) babies and majority of them $21 / 26$ (80.8\%) were referred to a second health care provider. One mother did not take the baby for formal healthcare citing that it was late at night and there was no available means of transport to the hospital. Mothers of three neonates who did not seek any care for their infants did not perceive the illness to be severe as to warrant immediate medical attention. 
Table 2: Symptoms neonates suffered before death

\begin{tabular}{|ll|}
\hline Symptoms & $\mathbf{n}(\%)$ \\
\hline Difficulty in breathing & $52(59.1 \%)$ \\
\hline Fast breathing & $11(12.5 \%)$ \\
\hline Felt cold to touch & $10(11.4 \%)$ \\
\hline Grunting & $6(6.8 \%)$ \\
\hline Fever & $5(5.7 \%)$ \\
\hline Chest In drawing & $4(4.5 \%)$ \\
\hline Vomiting & $2(2.3 \%)$ \\
\hline Wheezing & $1(1.1 \%)$ \\
\hline
\end{tabular}

*multiple symptoms reported

\section{Distribution of causes of death among preterm and LBW neonates}

Figure 3 below illustrates the distribution of causes of death by ICD 10 coding. Birth asphyxia (45.5\%), neonatal sepsis $(26.1 \%)$ and respiratory distress syndrome $(12.5 \%)$ were the three leading causes of neonatal deaths.

\section{Distribution of causes of death by discharge status and neonatal period}

Asphyxia, respiratory distress syndrome, and hypothermia, were the leading causes of death for babies who died before discharge. Neonatal sepsis was the leading cause of death for babies who were discharged from the health facility. In the early neonatal period (0-6 days) the leading causes of death were asphyxia (54.3\%), sepsis (15.7\%), respiratory distress syndrome (15.7\%), and hypothermia (10.0\%). Among late neonatal deaths (7-28 days), sepsis $(66.7 \%)$, hypothermia $(16.7 \%)$ and asphyxia $(11.1 \%)$ were the leading causes. See Table 3 below.

\section{Table 3: Causes of Death by Discharge Status and Neonatal Period}




\begin{tabular}{|c|c|c|c|c|}
\hline \multirow[t]{3}{*}{ Causes of death } & \multicolumn{2}{|c|}{ Discharge status } & \multicolumn{2}{|l|}{ Neonatal period } \\
\hline & $\begin{array}{l}\text { Pre- } \\
\text { discharge }\end{array}$ & $\begin{array}{l}\text { Post-discharge } \\
n=31\end{array}$ & $\begin{array}{l}\text { Early (0-6 days) } \\
n=70\end{array}$ & $\begin{array}{l}\text { Late (7-28 days) } \\
n=18\end{array}$ \\
\hline & $n=57$ & & & \\
\hline Asphyxia & $33(57.9)$ & $7(22.6)$ & $38(54.3)$ & $2(11.1)$ \\
\hline Sepsis & $6(10.5)$ & $17(54.8)$ & $11(15.7)$ & $12(66.7)$ \\
\hline $\begin{array}{l}\text { Respiratory distress } \\
\text { syndrome }\end{array}$ & $9(15.8)$ & $2(6.5)$ & $11(15.7)$ & $0(0)$ \\
\hline Hypothermia & $8(14.0)$ & $2(6.5)$ & $7(10.0)$ & $3(16.7)$ \\
\hline Prematurity & $0(0)$ & $2(6.5)$ & $2(2.9)$ & $0(0)$ \\
\hline $\begin{array}{l}\text { Extremely low birth } \\
\text { weight }\end{array}$ & $1(1.7)$ & $0(0)$ & $1(1.4)$ & $0(0)$ \\
\hline Severe anaemia & $0(0)$ & $1(3.2)$ & $0(0)$ & $1(5.6)$ \\
\hline
\end{tabular}

Distribution of age at the time of death in Figure 4 below indicates that the proportion of babies who died in the first week was $78.4 \%$. A total of $38(43.2 \%)$ neonates died within the first 24 hours and of these, $53 \%$ died pre-discharge.

\section{Death by gestational age}

Among children born less than 37 weeks, the proportion of death due to asphyxia was almost similar across the different gestational age groups. The proportion of death due to neonatal sepsis and respiratory distress syndrome increased with increasing gestational age peaking at $>/=32$ to $<37$, and declined slightly at $>/=37$, while deaths due to hypothermia reduced with increasing age (Figure 5).

\section{Discussion}

The leading probable causes of the neonatal death among preterm and LBW infants were birth asphyxia (45.5\%), neonatal sepsis (26.1\%), respiratory distress (12.5\%), and hypothermia (11\%). These findings reaffirm the report of other studies in Ethiopia and Bangladesh that indicate that preterm neonates die from conditions related to prematurity, as well as conditions not specifically related to prematurity [26] $[27,28][29]$.

Asphyxia accounted for almost half of all the neonatal deaths. This proportion is comparable to that reported in a rural sub-district in Bangladesh [30]. However, in a recent population-based study in several countries, Kenya reported lower proportions of deaths from birth asphyxia (32\%) and almost similar proportions for infections (28\%) [31]. A recent study from Ethiopia reported asphyxia as the cause in $14 \%$ 
of the deaths in neonates. The observed difference in higher proportion of deaths due to asphyxia in our study is possibly because of methodology issues. The Kenyan study was conducted among all neonates and not necessarily preterm or low birth weight infants while in the Ethiopian study though conducted among preterm infants implored clinical post mortem examinations in determining the cause of death.

Neonatal sepsis caused almost one-quarter of all deaths, the majority occurring after discharge. These proportions are similar to what is reported in other African countries ranging from $10-26 \%$ [32].

The distribution on causes of death in the early neonatal period is similar to results cited in other studies whereby the leading cause of death in early neonatal period is intrapartum while the leading cause of death in the late neonatal period is sepsis [33].

Physical characteristics and environmental factors predispose the preterm infant to hypothermia. In this study, we observed a low prevalence of both skin to skin contact and early initiation of breastfeeding within the first hour. Lack of these essential newborn practices may have resulted to the deaths due to hypothermia with the impact being higher among children born with lower gestational ages. To avert these deaths from hypothermia, proven low-cost yet lifesaving thermal care interventions of preterm babies, like early initiation to breastfeeding and practicing kangaroo mother care, is quite essential.

Preterm and LBW neonates are very vulnerable in the first week. Consistent with other studies, we found that more than three-quarters $(78.4 \%)$ of the neonatal deaths occurred in their first week of life and approximately half of these deaths occurred in the first 24 hours [33]. Thus, there is a need for refocused antenatal care, safe delivery practices and continuous engagement with mothers on the care of the preterm babies in and beyond the hospital walls.

All mothers were able to recognize signs and symptoms of illness their infants suffered and many sought formal health care for them. In most cases, the infants suffered multiple symptoms that would have benefitted from integrated management of neonatal and childhood health. As the majority of the deaths occurred in the health facilities, this points to the need of strengthening the health systems for the care of the preterm and LBW neonates to avert deaths. The reasons reported for not seeking formal care point to mothers' perceptions on illness severity to warrant hospital care and how distance to the hospital can be a limitation to seeking healthcare. The infant's illness may thus have become more severe as the mother awaited the following day to seek formal care.

\section{Limitations}

We assumed that the cause of death investigated had a set of observable symptoms that were easily recognized and recalled by the primary caregiver. We also note that causes of death have limited reliability when reported by lay-persons and can be subjective. The study only managed to interview half of the eligible participants, and it cannot be assumed that the others who passed away and were not available for the study died of similar causes. The study also provides no information for preterm and LBW babies who were born outside the health facilities and / or were not part of the parent study. 
However, we acknowledge the use of the standard tool for coding and interpretation of the causes of deaths. It is worthwhile to mention that the study population represented the county's high volume facilities, where it was likely that most preterm births occurred.

\section{Conclusion}

Birth asphyxia, neonatal sepsis, respiratory distress, and hypothermia, were the major causes of deaths of the neonates participating in the study. A big proportion of deaths happen immediately after birth up to the first 48 hours of life. It is important to note that all these conditions are preventable thus, enhancing low-cost life-saving interventions during the intrapartum care and the immediate neonatal period will go a long way to change this trend.

\section{Abbreviations}

CHERG: Child Health Epidemiology Reference Group

ICD-10: International Classification of Diseases

KEMRI: Kenya Medical Research Institute

PTBI-K: Preterm Birth Initiative-Kenya

SDG: Sustainable Development Goal

VASA: Verbal and Social Autopsy

WHO: World Health Organization

\section{Declarations}

\section{Ethics approval and consent to participate}

The study received approval from KEMRI's Scientific and Ethical Review Unit (SERU) approval number 3595. All study participants received full information about the study in their preferred local language and documented their willingness to participate by appending their signature on written informed consents.

\section{Consent for publication}

Not Applicable

\section{Availability of data and materials}

The datasets used to support the findings of this study are available from University of California San Francisco upon reasonable request and signing a data access agreement and subject to approval from 
the study principal investigators.

\section{Competing interests}

The authors declare they have no competing interest

\section{Funding}

This study was funded by the Bill Melinda Gates Foundation Bill \& Melinda Gates Foundation grant number 007991. The authors declare that the study design, data collection analysis and interpretation of the findings are independent of the funders input.

\section{Authors' contribution}

BO conceptualised the study, analysed the data and wrote the first draft of the manuscript.VM and CO contributed to design of the study, creation of data bases and data analysis, PAO contributed to design of the study, data management, manuscript development and review. GN and MI, participated in ICD 10 coding provided critical inputs for data interpretations, as well as review of the manuscript. NS contributed to conceptualization of the study, manuscript writing and consistent review of manuscript. P.O contributed in data collection, data entry as well as in manuscript writing. L.O contributed to conceptualization of the study, review and translation of the study documents. DW conceptualised the study review of manuscript draft and acquired funding for the study. All authors have read and approved the manuscript.

\section{Authors' affiliations}

Beatrice Olack ${ }^{1}$, Nicole Santos ${ }^{2}$, Mary Inziani ${ }^{1}$, Vincent Moshi ${ }^{1}$, Polycarp Oyoo ${ }^{1}$, Grace Nalwa ${ }^{3}$, Linet Ouma ${ }^{1}$ Christopher Otare ${ }^{1}$, Dilys Walker ${ }^{2}$, Phelgona Otieno ${ }^{1}$

1. Centre for Clinical Research, Kenya Medical Research Institute P.O Box 54840 00200, Nairobi Kenya.

2. University of California San Francisco, Institute for Global Health Sciences

3. Department of Paediatrics, School of Medicine, Maseno University

P.O Box Private Bag, Maseno Kenya.

\section{Acknowledgement}

We acknowledge the permission and support granted to us by the Migori County Health Department in the whole process from study initiation and implementation. We thank the PTBI-Kenya team that worked tirelessly to ensure data collection and data management for the study. We appreciate the effort provided by our collaborators from the UCSF at all levels of the study and manuscript review. We also acknowledge Kenya Medical Research Institute in providing, ethical approval and oversight for the study. 
We also thank the caregivers (who were mostly mothers of the deceased) for their willingness to participate in the study.

\section{References}

1. Black, R.E., et al., Global, regional, and national causes of child mortality in 2008: a systematic analysis. Lancet, 2010. 375.

2. Brankovic, S., et al., Incidence of morbidity and mortality in premature infants at the Department of Neonatal Intensive Care of Pediatric Clinic, Clinical Center of Sarajevo Unviersity. Med Arch, 2013. 67(4): p. 286-8.

3. Koffi, A.K., et al., Social determinants of child mortality in Niger: Results from the 2012 National Verbal and Social Autopsy Study. Journal of global health, 2016. 6(1): p. 010603-010603.

4. Lawn, J.E., K. Wilczynska-Ketende, and S.N. Cousens, Estimating the causes of 4 million neonatal deaths in the year 2000. Int J Epidemiol, 2006. 35(3): p. 706-18.

5. UNICEF: Levels and Trends in Child Mortality. Estimates Developed by the UN Inter-610 agency Group for Child Mortality Estimation. UN IGME Report. New York: UNICEF; 2015.

6. Abdel Razeq, N.M., Y.S. Khader, and A.M. Batieha, The incidence, risk factors, and mortality of preterm neonates: A prospective study from Jordan (2012-2013). Turk J Obstet Gynecol, 2017. 14(1): p. 28-36.

7. Katz, J., et al., Mortality risk in preterm and small-for-gestational-age infants in low-income and middle-income countries: a pooled country analysis. Lancet, 2013. 382(9890): p. 417-425.

8. Ludvigsson, J.F., et al., Small for gestational age and risk of childhood mortality: A Swedish population study. PLoS medicine, 2018. 15(12): p. e1002717-e1002717.

9. http://www.who.int/maternal_child_adolescent/documents/born_too_soon/en/.

10. Lawn, J.E., K. Wilczynska-Ketende, and S.N. Cousens, Estimating the causes of 4 million neonatal deaths in the year 2000. International Journal of Epidemiology, 2006. 35(3): p. 706-718.

11. Blencowe, H., et al., Born too soon: the global epidemiology of 15 million preterm births. Reproductive health, 2013. 10 Suppl 1(Suppl 1): p. S2-S2.

12. WHO, Global nutrition targets 2025: childhood overweight policy brief. Geneva: World Health World Health Organization:

http://www.who.int/nutrition/publications/globaltargets2025_policybrief_overweight/en/. 2014.

13. Lawn, J.E., et al., Born too soon: care for the preterm baby. Reproductive health, 2013. 10 Suppl 1(Suppl 1): p. S5-S5.

14. WHO, Every Newborn Action Plan, An Action Plan To End Preventable Deaths http://www.everynewborn.org/Documents/Executive-summary\%20_EN.pdf).

15. UNICEF, Committing to Child Survival: A Promise Renewed. Progress Report 2014.

16. Joy Lawn, Pyande Mongi, and S. Cousens, Africa's newborns-counting them and making them count, in Opportunities for Africa's Newborns, WHO: WHO, Geneva. 
17. Kenya National Bureau of Statistics and, I.C.F.I., Kenya Demographic and Health Survey, Key Indicators. 2015, ICF International Rockville, MD.

18. D'Ambruoso, L., et al., A lost cause? Extending verbal autopsy to investigate biomedical and sociocultural causes of maternal death in Burkina Faso and Indonesia. Soc Sci Med, 2010. 71(10): p. 1728-38.

19. Kalter, H.D., et al., Verbal/social autopsy study helps explain the lack of decrease in neonatal mortality in Niger, 2007-2010. J Glob Health, 2016. 6(1): p. 010604.

20. Koffi, A.K., et al., Social determinants of child mortality in Niger: Results from the 2012 National Verbal and Social Autopsy Study. J Glob Health, 2016. 6(1): p. 010603.

21. Koffi, A.K., et al., Social autopsy study identifies determinants of neonatal mortality in Doume, Nguelemendouka and Abong-Mbang health districts, Eastern Region of Cameroon. J Glob Health, 2015. 5(1): p. 010413.

22. McCaw-Binns, A., J. Mullings, and Y. Holder, The Quality and Completeness of 2008 Perinatal and Under-five Mortality Data from Vital Registration, Jamaica. The West Indian medical journal, 2015. 64(1): p. 3-16.

23. Arudo, J., et al., Comparison of government statistics and demographic surveillance to monitor mortality in children less than five years old in rural western Kenya. Am J Trop Med Hyg, 2003. 68(4 Suppl): p. 30-7.

24. Otieno, P., et al., Strengthening intrapartum and immediate newborn care to reduce morbidity and mortality of preterm infants born in health facilities in Migori County, Kenya and Busoga Region, Uganda: a study protocol for a randomized controlled trial. Trials, 2018. 19(1): p. 313.

25. Nichols, E.K., et al., The WHO 2016 verbal autopsy instrument: An international standard suitable for automated analysis by InterVA, InSilicoVA, and Tariff 2.0. PLoS medicine, 2018. 15(1): p. e1002486e1002486.

26. Halder, A.K., et al., Causes of Early Childhood Deaths in Urban Dhaka, Bangladesh. PLOS ONE, 2009. 4(12): p. e8145.

27. Edmond, K.M., et al., Aetiology of stillbirths and neonatal deaths in rural Ghana: implications for health programming in developing countries. Paediatr Perinat Epidemiol, 2008. 22(5): p. 430-7.

28. Fottrell, E., et al., Cause-specific neonatal mortality: analysis of 3772 neonatal deaths in Nepal, Bangladesh, Malawi and India. Archives of Disease in Childhood - Fetal and Neonatal Edition, 2015. 100(5): p. F439.

29. Goldenberg, R.L., et al., Criteria for assigning cause of death for stillbirths and neonatal deaths in research studies in low-middle income countries. J Matern Fetal Neonatal Med, 2018. 32(11): p. 1915-1923.

30. Chowdhury, H.R., et al., Causes of neonatal deaths in a rural subdistrict of Bangladesh: implications for intervention. J Health Popul Nutr, 2010. 28(4): p. 375-82.

31. Ahmed, I., et al., Population-based rates, timing, and causes of maternal deaths, stillbirths, and neonatal deaths in south Asia and sub-Saharan Africa: a multi-country prospective cohort study. The 
Lancet Global Health, 2018. 6(12): p. e1297-e1308.

32. Liang L, et al., Predictors of Mortality in Neonates and Infants Hospitalized With Sepsis or Serious Infections in Developing Countries: A Systematic Review Frontiers in Pediatrics 2018. 6 p. 277.

33. Mengesha, H.G. and B.W. Sahle, Cause of neonatal deaths in Northern Ethiopia: a prospective cohort study. BMC Public Health, 2017. 17(1): p. 62.

\section{Figures}

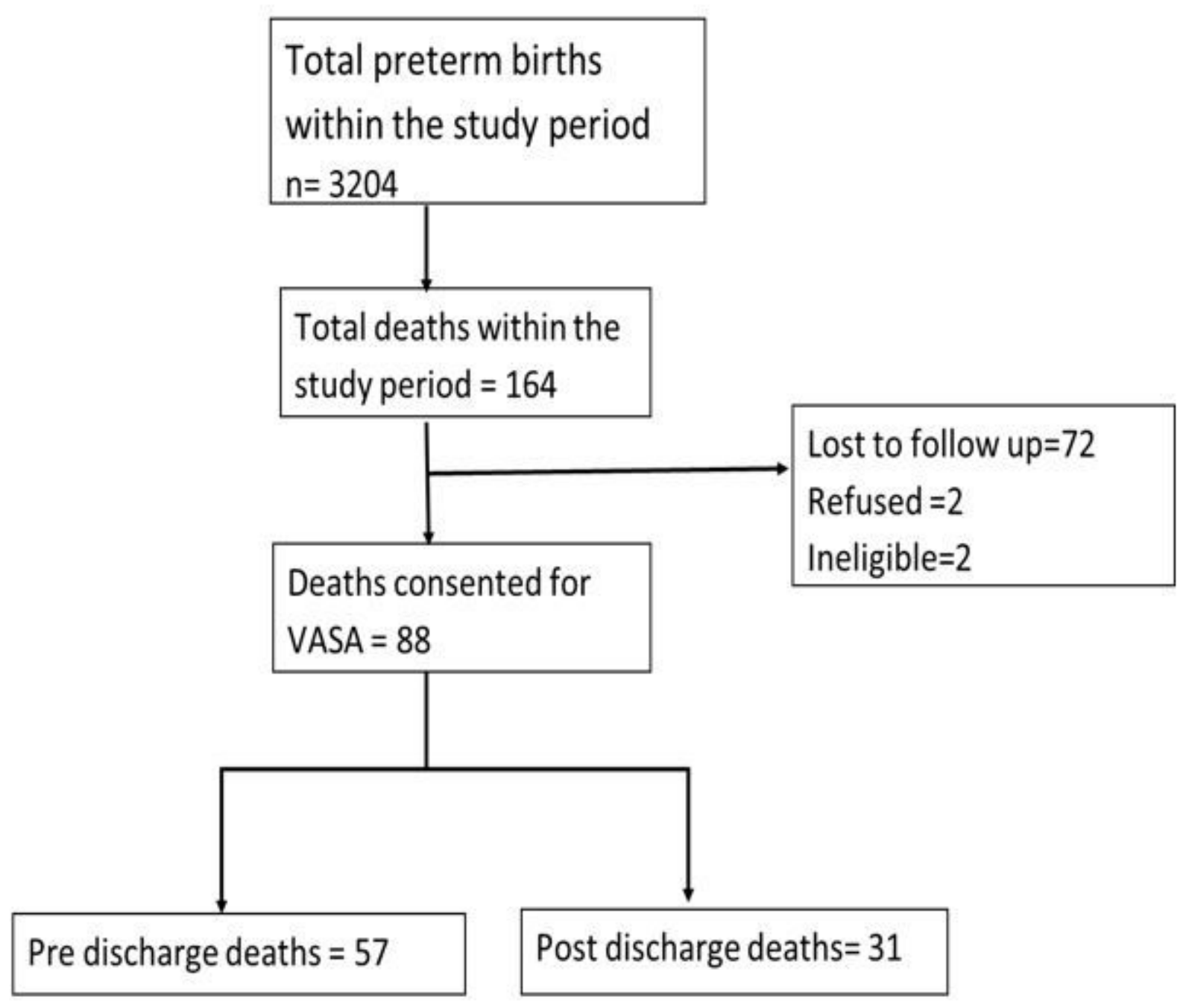

Figure 1

Flow of the Study Participants 


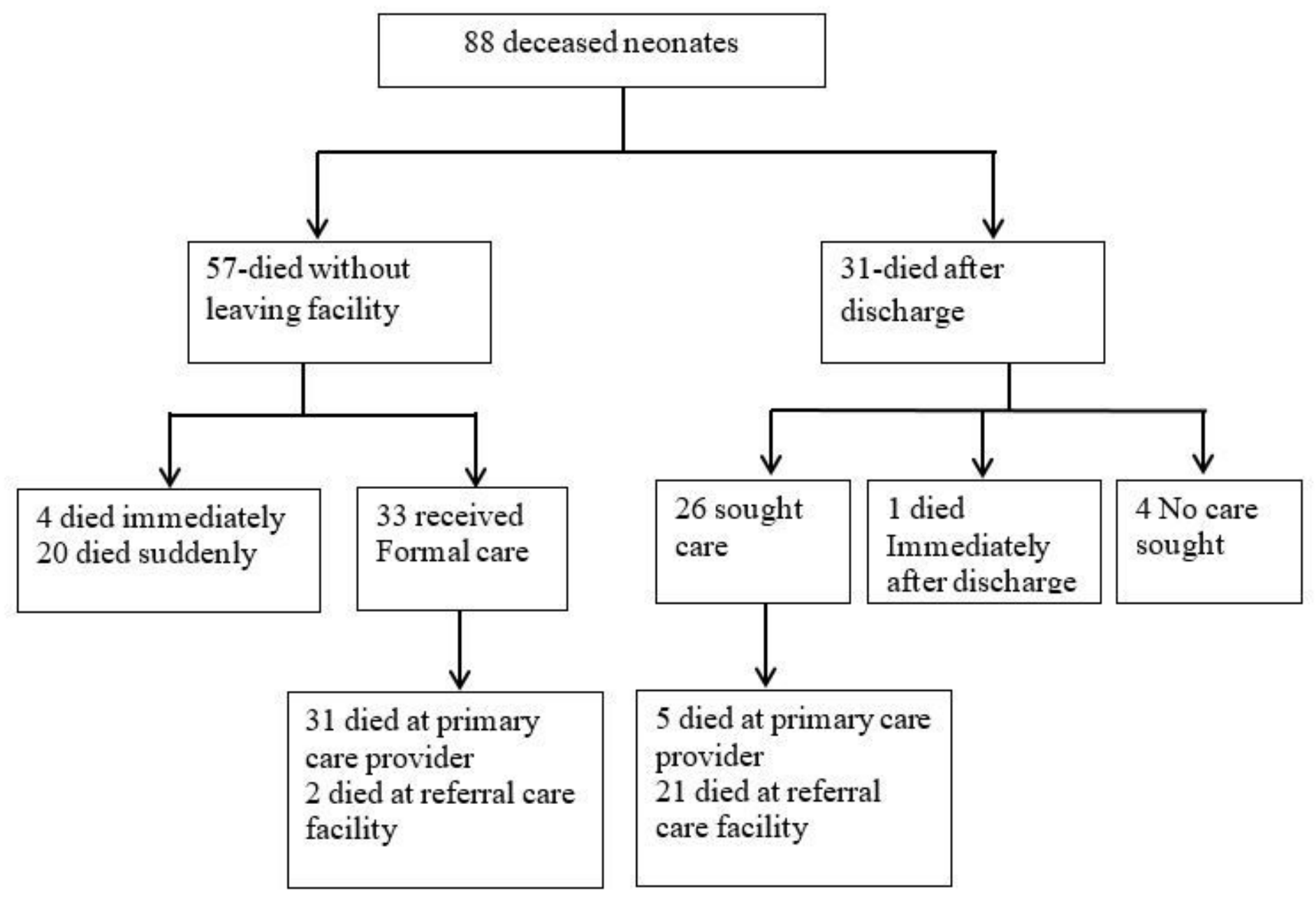

Figure 2

Pathway to seeking care for 88 neonatal deaths 


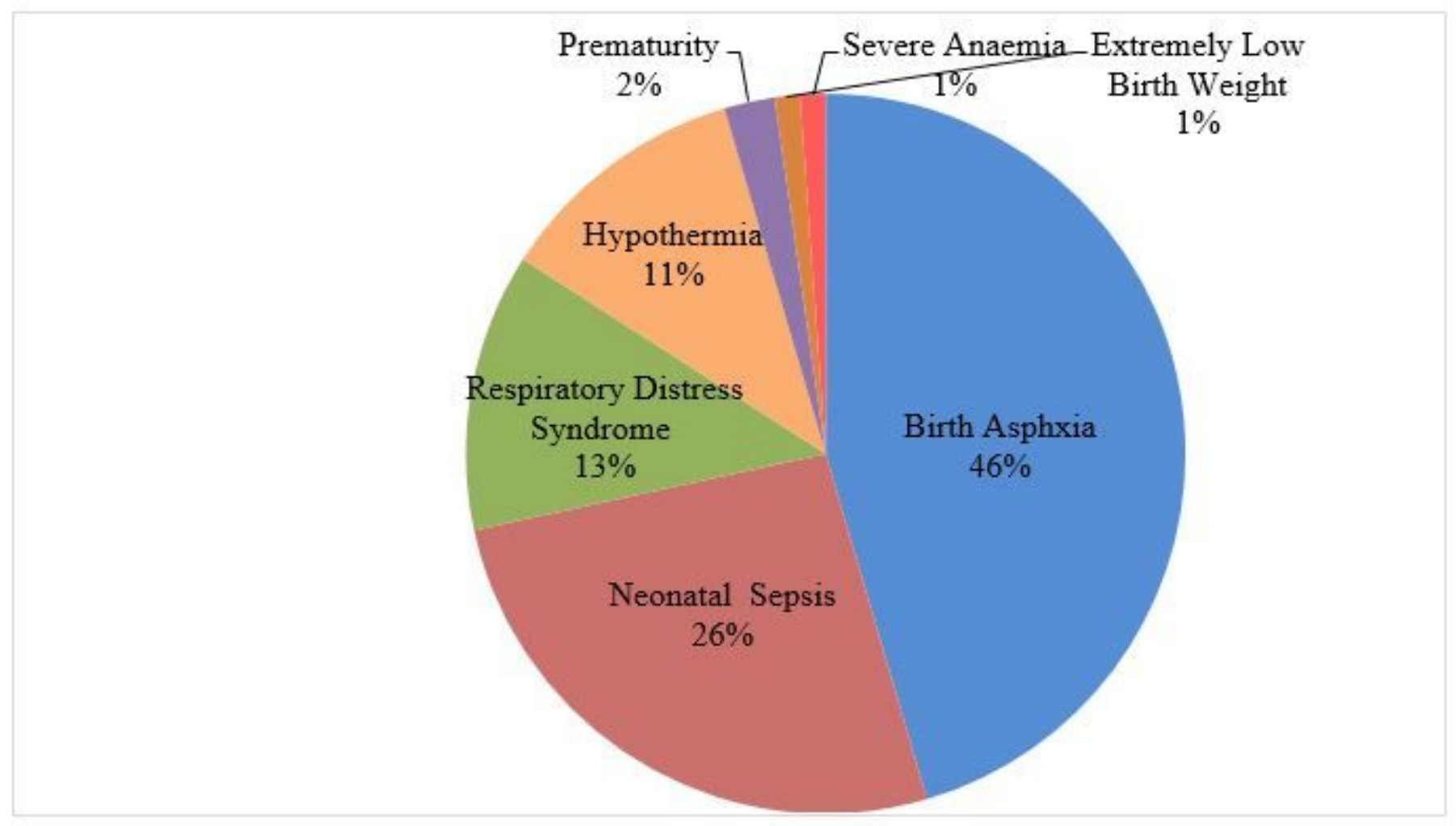

Figure 3

Causes of death among preterm and low birth weight neonates

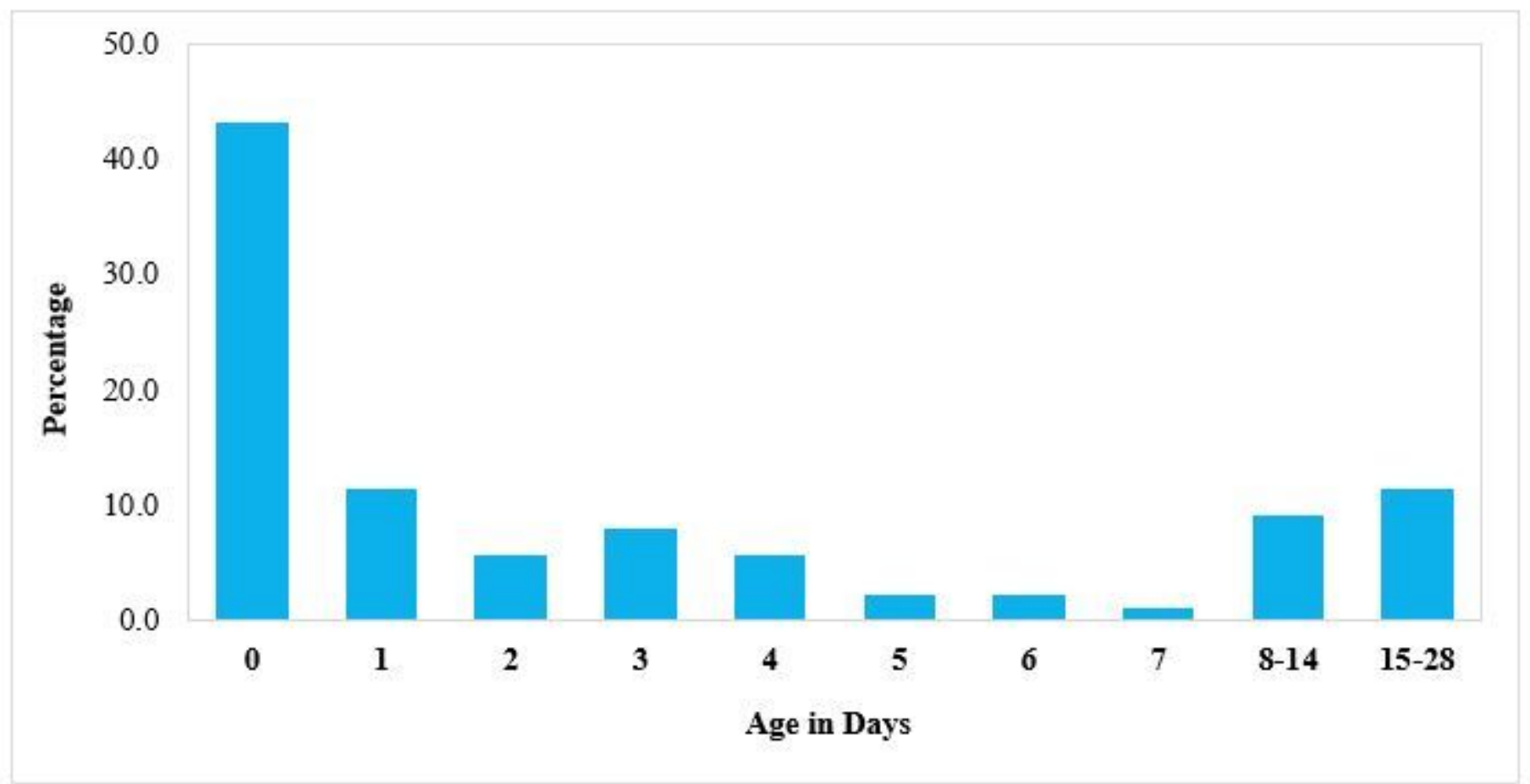

Figure 4

Neonates age at the time of death in days 


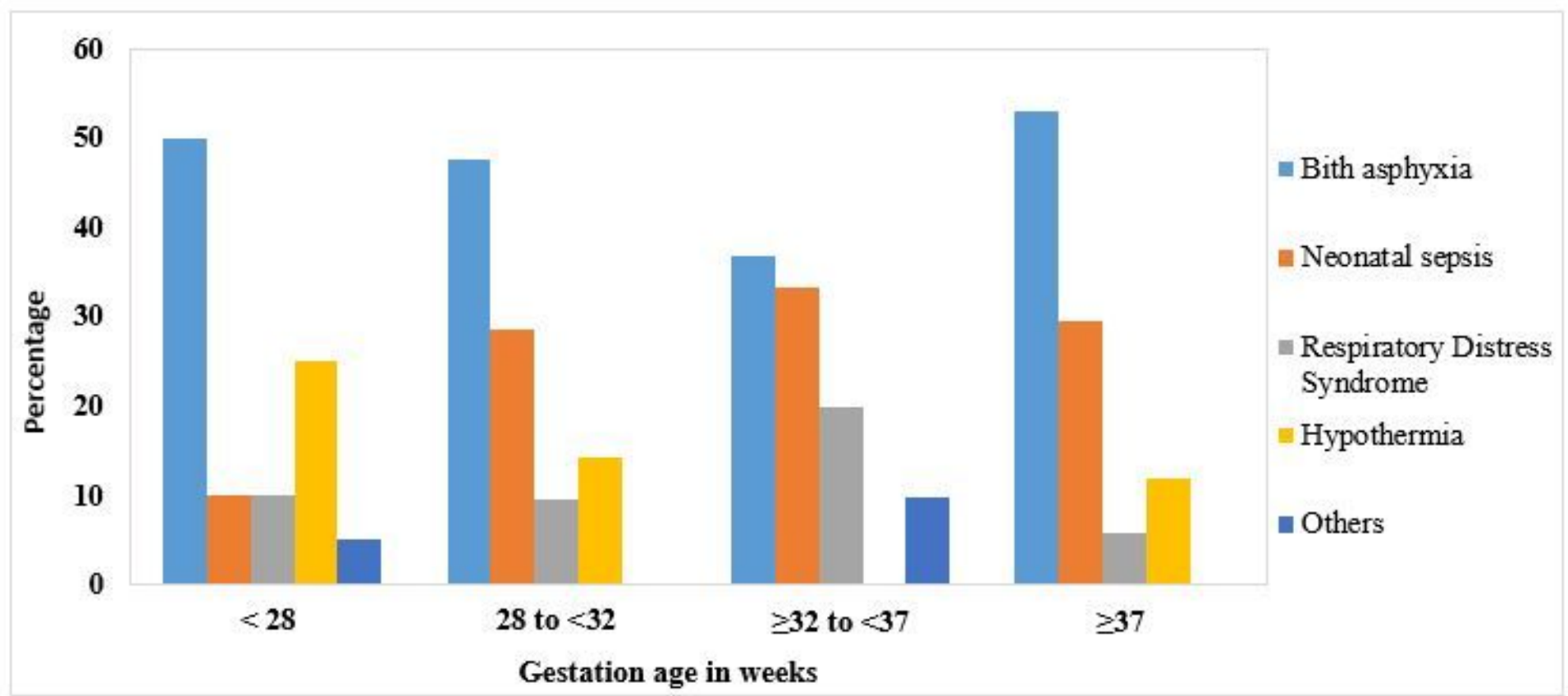

Figure 5

Causes of Death Stratified by Gestational Age

\section{Supplementary Files}

This is a list of supplementary files associated with this preprint. Click to download.

- STROBEchecklistVASAcrosssectional.doc 